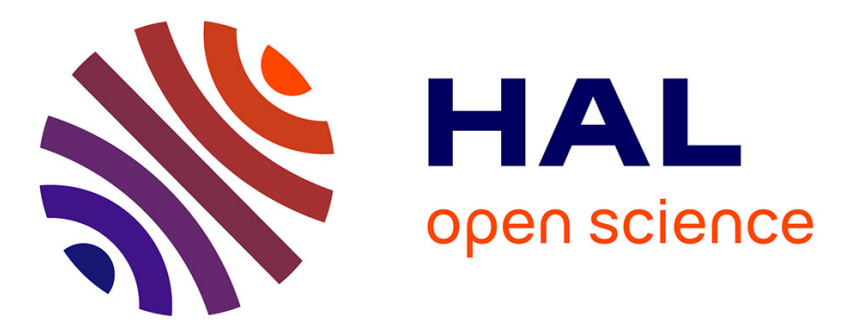

\title{
Early stages of apparel design : how to define collaborative needs for PLM and fashion?
}

Frédéric Segonds, Fabrice Mantelet, Nicolas Maranzana, Stéphane Gaillard

\section{To cite this version:}

Frédéric Segonds, Fabrice Mantelet, Nicolas Maranzana, Stéphane Gaillard. Early stages of apparel design: how to define collaborative needs for PLM and fashion?. International Journal of Fashion Design, Technology and Education, 2014, 7 (2), pp.105-114. 10.1080/17543266.2014.893591 . hal$01091287 \mathrm{v} 2$

\section{HAL Id: hal-01091287 \\ https://hal.science/hal-01091287v2}

Submitted on 16 Mar 2015

HAL is a multi-disciplinary open access archive for the deposit and dissemination of scientific research documents, whether they are published or not. The documents may come from teaching and research institutions in France or abroad, or from public or private research centers.
L'archive ouverte pluridisciplinaire HAL, est destinée au dépôt et à la diffusion de documents scientifiques de niveau recherche, publiés ou non, émanant des établissements d'enseignement et de recherche français ou étrangers, des laboratoires publics ou privés. 


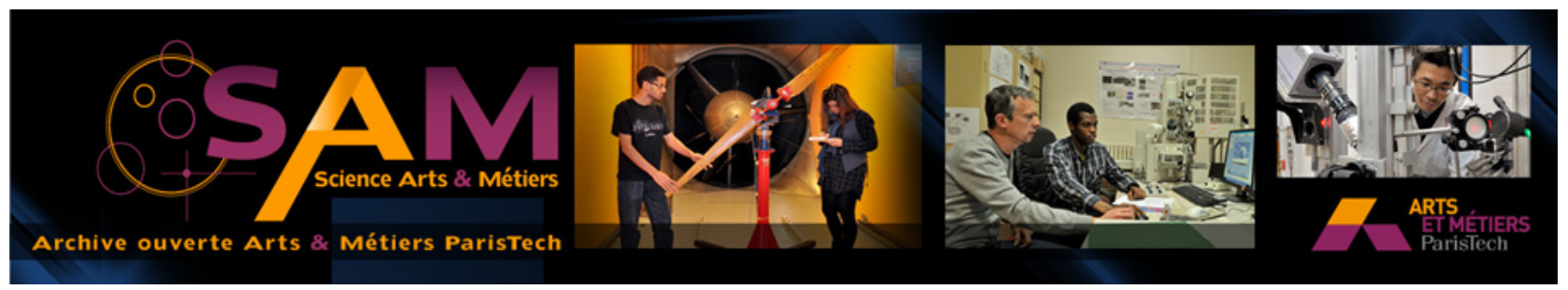

\section{Science Arts \& Métiers (SAM)}

is an open access repository that collects the work of Arts et Métiers ParisTech researchers and makes it freely available over the web where possible.

This is an author-deposited version published in: http://sam.ensam.eu

Handle ID: .http://hdl.handle.net/10985/9063

\section{To cite this version :}

Frédéric SEGONDS, Fabrice MANTELET, Nicolas MARANZANA, Stéphane GAILLARD - Early stages of apparel design: how to define collaborative needs for PLM and fashion? - International Journal of Fashion Design, Technology and Education - Vol. 7, n², p.105-114 - 2014 


\title{
Early stages of apparel design: how to define collaborative needs for PLM and fashion?
}

\author{
Frederic Segonds $^{\mathrm{a} *}$, Fabrice Mantelet $^{\mathrm{a}}$, Nicolas Maranzana $^{\mathrm{a}}$ and Stephane Gaillard ${ }^{\mathrm{b}}$ \\ ${ }^{a}$ LCPI, Arts et Metiers ParisTech, 151 bd de l'hopital, Paris 75013, France; ${ }^{b}$ Devanlay, 22 rue de Provence, Paris 75009 , France
}

\begin{abstract}
Companies are faced with increasing challenges in their own environment. In several areas of the industry, but also among the suppliers, more and more competitors emerge. Companies react to this pressure by trying to implement new technologies for their products and offering more innovative products to successfully face direct competition. Overall, globalisation put pressure on companies in terms of innovation, costs and time to market. This climate of economic competition forces businesses to adapt to the expectations of their customers. To achieve this change, it becomes necessary amongst other things to reduce design time. Thus, practices in apparel design have evolved in order to be able to manage projects in new work environments. After presenting a literature review of collaborative functionalities used in product design, our paper presents an illustration of a case study for Product Lifecycle Management research in the apparel industry, focusing on the definition of needs in terms of collaborative functions to support the design of apparel products, in an industrial context.
\end{abstract}

Keywords: fashion; apparel design; CAD; PLM

\section{Introduction}

Industries today must face the increasing complexity of their work environment and activities: globalisation of their markets, increasing distance between industrial partners, pressures related to costs, proliferation of information, reduced time to market and emergence of code signing practices involving suppliers. This has gradually led to Business Process Outsourcing, one of the most important changes in design practices in the first decade of the twenty-first century, experienced by many different professions (Pezeshki, Frame, \& Humann, 2004).

Product Lifecycle Management (PLM) is both a company strategy and a specialised information system (IS). It unites the various data and processes related to the product, allowing the many types of professionals involved to share this information within collaborative environments.

Functionalities afforded by PLM tools (Maranzana, Segonds, Lesage, \& Nelson, 2012) generally include managing technical data, managing configurations and tools in distributed collaborative design (Johansen, 1988). Figure 1 illustrates current developments in the constitution of product development teams. These tend to be increasingly collaborative and virtualised.

The Devanlay group holds an exclusive license with the Lacoste clothing brand. Our industrial study took place mainly on the Paris site, where is located, in particular, the group's creation and marketing divisions. This office collaborates closely with a central development platform located in Troyes, France, which is in charge of product development.

In the apparel industry, the development cycle includes every stage from product launch up to withdrawal of the product from the market, but it is the stages of product definition and development which are the most demanding stages in terms of time and financial resources. Furthermore, the development cycle is unchanging, and corresponds to one season (there are two seasons per year). For example, Figure 2 illustrates variations in stock size throughout the various stages of the product development cycle, in the case of a polo shirt - Lacoste's best-selling item. Many of the stages in this process can also be found in a classical product design process (needs analysis, conceptual design, implementation, etc.) as defined in (Howard, Culley, \& Dekoninck, 2008) and (Pahl, Beitz, Feldhusen, \& Grote, 2007). Other stages are more specific, such as structuring the collection, or restocking. Restocking involves reorganising the stock of needed items, but can also refer to reordering items from suppliers in the event of unexpectedly high sales. Production volumes are approximately 250,000 items per reference. One element that is specific to the design of a collection of clothing, for the purpose of selling these items to wholesale dealers or salespersons, is organising a convention in order to present the items of the collection, to start the ordering phase, and to launch large-scale manufacturing of the items.

\footnotetext{
*Corresponding author. Email: frederic.segonds@ensam.eu
} 


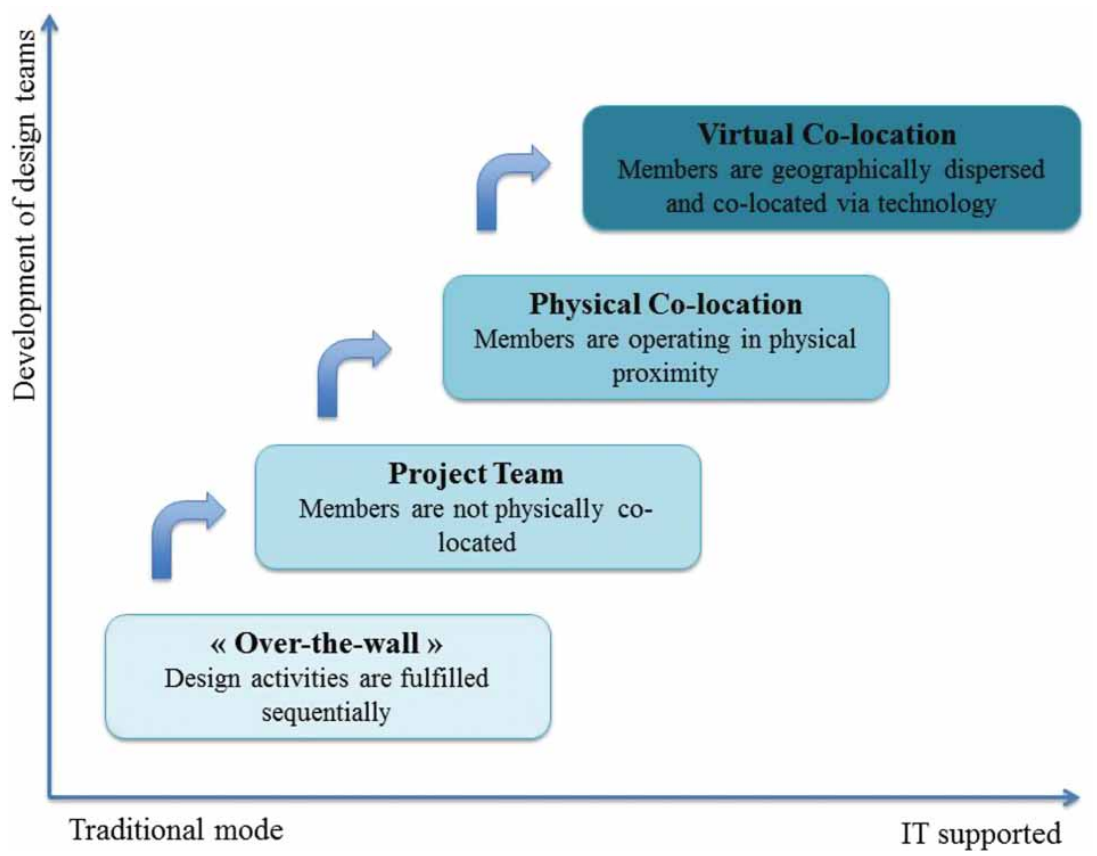

Figure 1. Changing in design teams adapted from (Sharifi \& Pawar, 2001).

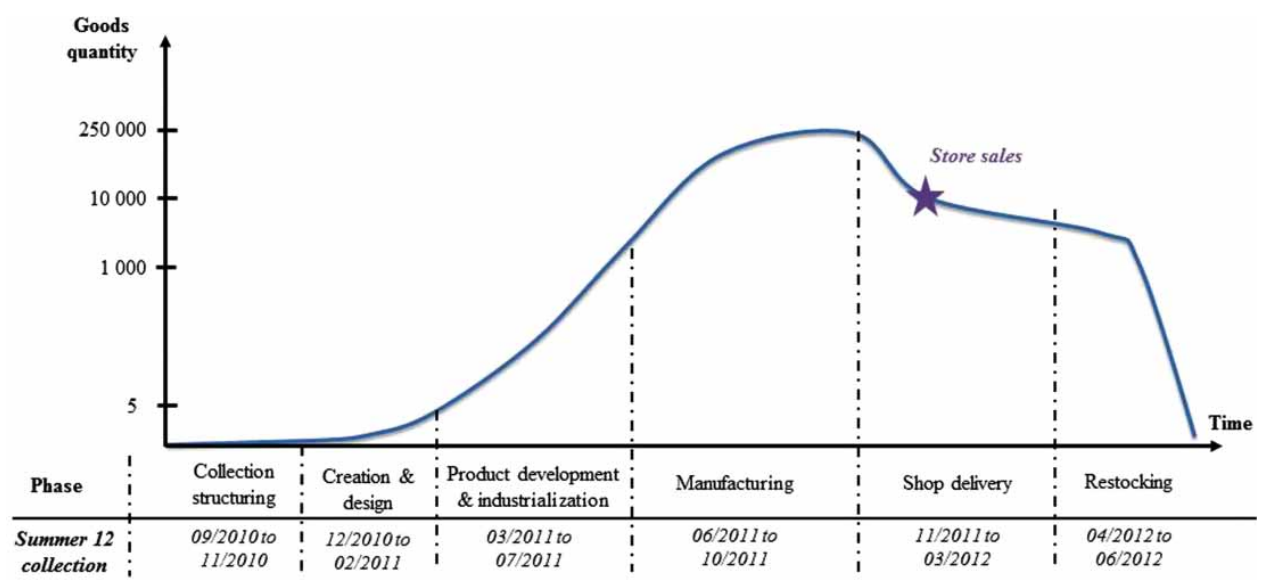

Figure 2. Changes in stock for one item over the course of one season, for example, a white polo shirt.

\section{PLM definition and its integration in the industry}

\subsection{The evolution of methods in collaborative product design}

In this part, we realise a chronological literature review of the methods applied in the business world in order to improve competitiveness. These methods, applied in the industrial world, seem to be at the heart of the issue of reducing product development time, which many businesses in the apparel industry currently face.

\subsubsection{Concurrent engineering}

Towards the end of the 1980s and the beginning of the 1990s, two forms of design organisation emerged as distinct alternatives: sequential design, which involves carrying out design tasks one after the other, and concurrent engineering (CE), or integrated design (Prasad, 1996; Sohlenius, 1992; Winner, Pennell, Bertrand, \& Slusarczuk, 1988). Two of the characteristics of $\mathrm{CE}$ that distinguish it from conventional approaches to product development are cross-functional integration and concurrency. In sequential engineering, exchanges between actors are based on direct relationships. In $\mathrm{CE}$, one must define shared interfaces between the various tasks. Indeed, $\mathrm{CE}$ is an approach to product development, in which considerations about product lifecycle processes, from product planning, design, production to delivery, service, and even end-of-life, are all integrated. By carrying out all these tasks in a parallel fashion, it becomes possible to reduce the time and costs of design, but also to improve the quality of products. 
With the development of Information Technology, CE methods have evolved gradually towards collaborative engineering.

\subsubsection{Collaborative engineering}

Collaborative engineering emerged in the 1990s as an approach to structure the collective aspects of product and system design. In collaborative engineering, as in CE, overlapping tasks are still present, but project stakeholders are requested to work together and interact with each other in order to reach an agreement and make shared decisions. The degree of collaboration is discussed here based on the level of decision coupling. Designers from the whole group work together to design the product that is viewed as a response to customer needs. Collaborative activity is synchronised and coordinated throughout the process of collaboration.

Thus, whereas synergy is created between project actors in collaborative engineering, PLM ensures that synergy is created throughout the whole of the product lifecycle.

\subsubsection{Product Lifecycle Management}

In the early 2000s, PLM emerged as a solution to adapt engineering design to the demands of globalisation. Indeed, as PLM addresses the entire lifecycle of the product, it has a cross-functional nature and deals closely with the way a company runs (Garetti, Terzi, Bertacci, \& Brianza, 2005). Collaborative design has been the subject of numerous studies. With the development of Product Data Management (PDM), PLM and associated workflows, software firms have proposed solutions to the everyday problems of engineering design departments (versioning of documents, naming etc.). PLM aims to cover all the stages of product development, by integrating the processes and people taking part in the project (Schuh, Rozenfeld, Assmus, \& Zancul, 2008). This concept is generally used in the context of industrial products. According to Amann (2002), PLM has emerged in the early twenty-first century as a term to describe a business approach for the creation, management, and use of product-associated intellectual capital and information throughout the product lifecycle. Thus, PLM is an approach in which processes are just as important as data, or even more so. The PLM approach can be viewed as a trend toward a full integration of all software tools being used in design and operational activities during a product's lifecycle (Garetti et al., 2005). Therefore, PLM software packages need PDM systems, as well as synchronous and asynchronous, local and remote collaboration tools and if necessary, a digital infrastructure allowing exchanges between software programs.

\subsection{Current PLM solutions and related features}

Current PLM tools offer functionalities that can be found in most software solutions (Le Duigou, Bernard, \& Perry,
2011). These can be classified into three main categories: PDM, configuration management, and distributed design tools.

The main functionalities found in PDM tools are as follows:

- Access rights management: depending on the user's clearance level, he or she is given access to information contained within the PLM system. Depending on this clearance level, the actions available to users may be restricted (regarding reading, writing, and modification of documents). Concepts of roles and groups are often present in such systems. Roles refer to predefined access rights that administrators may ascribe to users. Groups are sets of users with similar rights.

- Vaults: datasets and related documents are stored in a server called a vault, as opposed to being stored locally on the user's computer. Data are stored in an object or a relational database. Hence, information is structured according to the data model implemented within the database. Documents are stored in the server. When a document is opened, it is replicated in the user's workstation, for a duration that depends on the software considered.

- Document visualisation. Users are able to rapidly visualise documents in various formats, without owning the application that corresponds to a particular file format.

- Check-out and check-in. This functionality allows users to check out a document in order to ensure that no other user working on the document at the same time may alter it. Once the document has been edited, the user checks the document back in to make it accessible to other users once again.

- Document versioning. Several versions of the same document may be archived. Two levels are used for versioning. The terms used are 'version' (the higher level, generally indicated with a letter such as A, B, etc.) and 'revision' (the lower level, usually indicated with a number, 1, 2, etc.). This system is used to distinguish major alterations from minor alterations.

- States. Various states are associated with each document. These help define their level of maturity: creation, validation, obsolescence, etc. Changes in these states may be decided based on the workflow, e.g. 'awaiting validation': project members will await the project manager's authorisation to carry out subsequent operations.

- Workflows. These systems make it possible to model processes and to automate actions. These systems are mostly used in validation processes for documents and technical data.

Configuration management consists of controlling information related to product structure, especially by breaking it down into elementary parts, and adding information 
related to their functional and physical characteristics (Zina, Lombard, Lussent, \& Henriot, 2006). The ISO 10007 standard (ISO, 2003) includes recommendations for using configuraltion management in the industry. It provides the detailed process, organisation and procedures for configuration management. According to this standard, this configuration management is an integral part of PLM. It provides a clear vision of the configuration state associated with a product or project, as well as their evolutions by guaranteeing total traceability (ISO, 2003).

In the field of the apparel industry, concepts of configuration and traceability are essential. Indeed, each collection numbers thousands of references, and each item of clothing corresponds to a pattern, which is given a specific colour and size, as it is destined for a target customer. Thus, configuring an item of clothing takes into account the following characteristics:

- The item reference

- The colour, size, and universe

- The product line: knitwear, pullovers, and accessories

- The target market and production platform

- The patterning

- The related bill of material, which takes into account the regulatory constraints of the target market

- Cost and selling prices, which depend on the distribution channel

Distributed design tools (Johansen, 1988) allow users to share a screen, to remotely gain control over another user's workstation, and to exchange instant messages. They also allow the use of a webcam to visualise a colleague, or of VoIP to talk with him/her.

PLM is currently evolving towards PLM 2.0, which takes advantage of the intelligence that is collectively generated by online communities. In this view, all users may imagine, share, and experiment with 3D products. Current software editors take a holistic approach when designing ISs in companies. This poses the question of adapting their software to the company's organisational context, as well as the question of the compatibility of ISs within the company. Implementing an integrated IS - or more simply, a shared information system - should never hinder the development of a company (El Kadiri, Pernelle, Delattre, \& Bouras, 2009).

Therefore, the functionalities described in this section must be integrated when choosing and deploying a PLM tool in the specific field of the apparel industry. In the section below, we analyse the constraints involved when applying these functionalities to the case of designing an apparel product.

\subsection{PLM solutions for apparel design}

PLM tools are mainly derived from CAD software editors (Maranzana et al., 2012). Therefore the development of PLM in the apparel industry closely follows the development of CAD in this sector. However, the use of CAD systems in clothing design is still quite restricted. There are two main reasons for this. First, CAD tools investments are difficult to justify for businesses whose main investments lie in raw materials. Second, design relies entirely on the use of patterns, which are two-dimensional. These patterns are then assembled to form an item of clothing (see Figure 3). Since items of clothing are flexible, the types of constraints used in design depend on the pattern makers' experience, and are determined on a case-by-case basis. The well-recognised flowchart of CAD systems for 2D clothing includes the stages of fashion style design, pattern design, pattern grading and marker making (Liu, Zhang, \& Yuen, 2010). For example, typical commercial CAD software for 2D clothing includes Gerber in the USA, Shima Seiki in Japan or Lectra and Vetigraph in France.

A further contribution of CAD in apparel design is the ability to carry out mechanical simulations in order to verify that the design matches the specifications supplied. These digital simulations have made it possible to drastically reduce development times in industrial product design. They rely on modelling systems, e.g. finite element modelling. In the apparel industry, modelling is a far more subjective matter. Consequently, its use is not quite so widespread. Indeed, designing and simulating virtual items of clothing involve combining a wide range of techniques, with mechanical simulation, collision detection, and user interface techniques, all of which are adapted
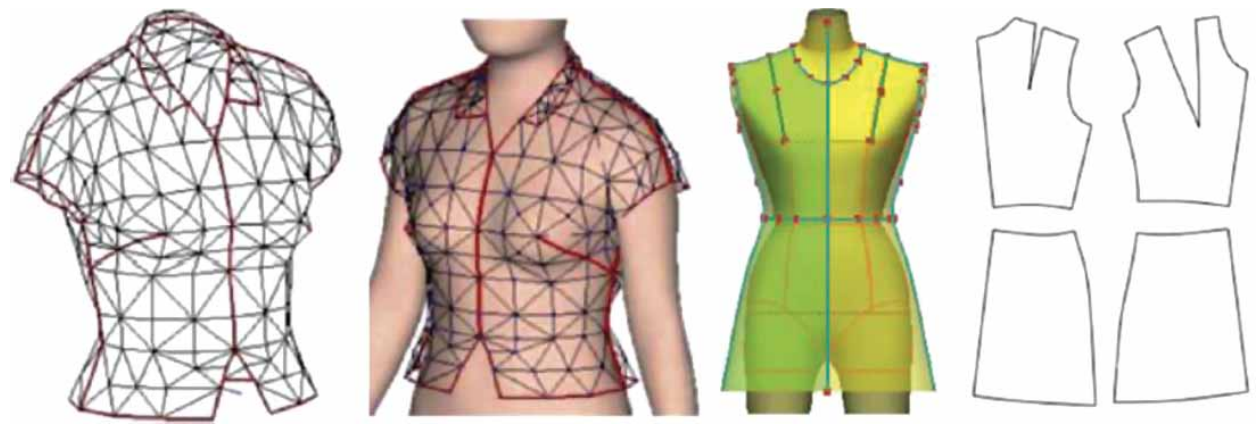

Figure 3. A 2D-to-3D transformation and simulation model used in the apparel industry, courtesy of Liu et al. (2010). 


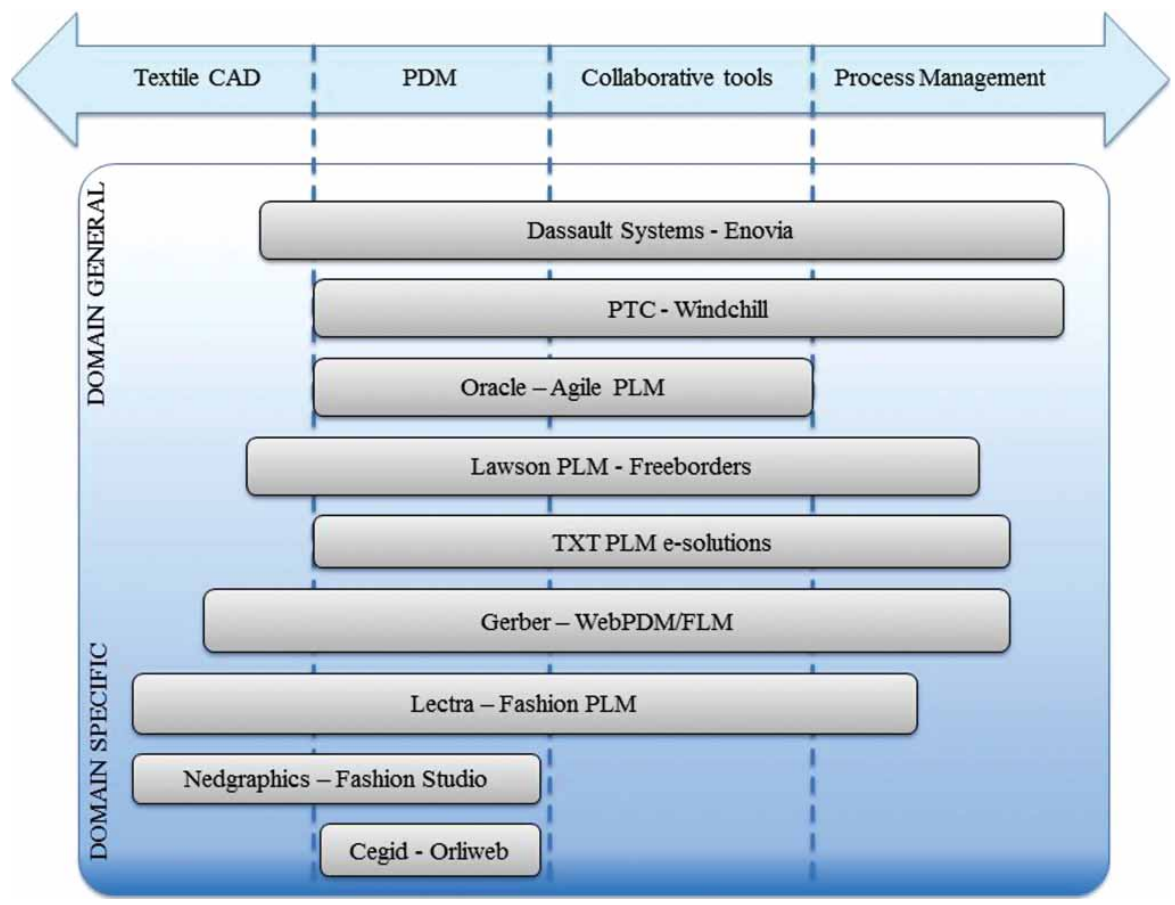

Figure 4. Functionalities of various PLM systems, adapted to the apparel industry.

to the creation of items of clothing (Volino, Cordier, \& Magnenat-Thalmann, 2005). Simulation tools are complex and take advantage of algorithms from the field of mechanical simulation, animation and rendering.

\subsection{A comparison of different tools PLM in the apparel industry}

In order to choose a suitable PLM solution, it is crucial to carry out a technical study of the functionalities present in various available commercial solutions. We have tested, in an industrial context, the skill of various commercial solutions to respond to designer requirements.

These solutions were tested within the Devanlay company. Our evaluation was based on our use of the various pieces of software tested, running on a dedicated machine, and on our attendance of various technical presentations of these pieces of software. The tests took place over a period of three months, at the head office of Devanlay in Paris. Following the presentation of 'industrial' PLM tools (Maranzana et al., 2012); it can be noted that every piece of PLM software cannot easily be adapted for use in the apparel industry. Indeed, whereas some software editors focus heavily on PDM, collaborative, and process management functionalities (e.g. Dassault Systems and PTC), other editors focus on apparelspecific CAD functionalities (e.g. Lectra and Nedgraphics). Figure 4 compares various solutions with different criteria.

Following this review, it can be noted that there currently exists no turnkey software solution which would provide all the functionalities expected of a PLM system suited to the apparel industry. Consequently, the chosen tools must provide an adequate answer to the analysis of user needs, in the context of multi-user collaborations. Such user needs analysis may rely on interviews with representatives of the software's end-users (Holzinger, 2005; Maguire, 2001).

\subsection{Research questions and methodological proposal}

As this literature review suggests, PLM is one of the major evolutions in the practice of innovative design in recent years and has led to the development and diffusion of numerous software solutions. However, it also suggests that the apparel industry presents a number of unique characteristics and requirements from the point of view of the design of tools to assist PLM, leading to the following question: do the available tools truly address the needs of professionals in the apparel industry, particularly in collaborative design teams? To answer this question, we have carried out a case study based on the principles outlined by Dul and Hak (2008). We will present the context of our intervention, corresponding to what these authors call the stages of problem finding and problem diagnosis. To answer the research question noted above - focusing on user requirements analysis - we carried out a series of user interviews focusing on the kind of media used to support communication in collaborative work. In the section below, we present the field work we carried out in order to formalise end-user requirements, throughout the course of collaboration with the Devanlay company. 


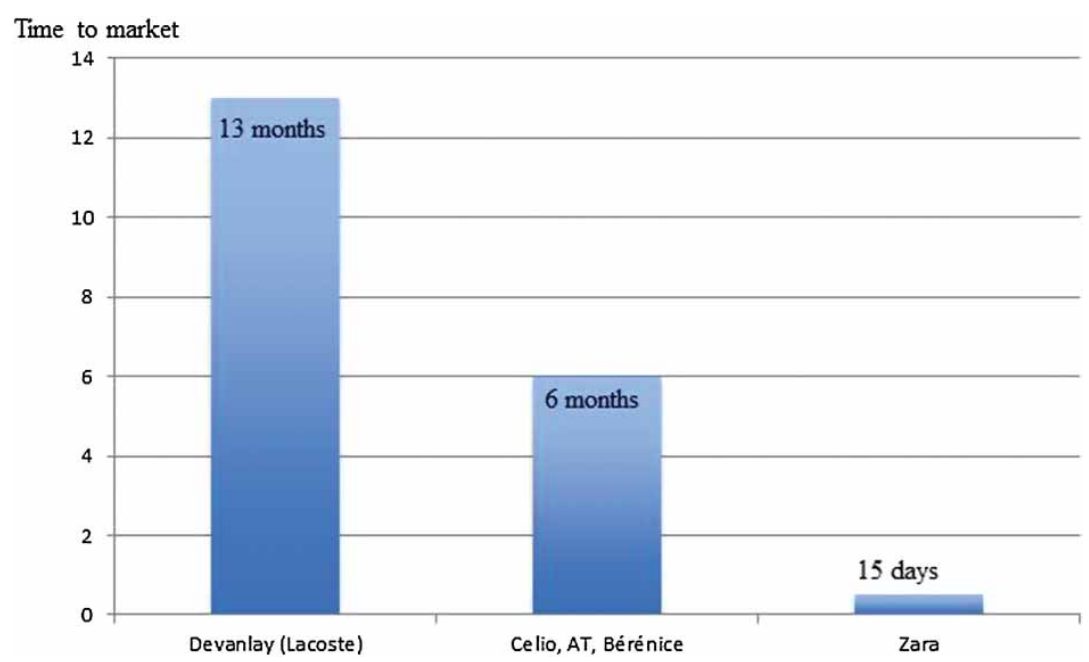

Figure 5. Examples of times to market in the apparel industry.

\section{A case study in the apparel industry: the Devanlay company}

\subsection{Interview protocol}

To analyse the collaborative specifications necessary for design, we performed a need analysis with the users of the company Devanlay. The user interview is a method used to collect oral data from individuals or groups in order to derive information from specific facts or representations. The relevance, validity, and reliability of this information are assessed based on the goals of this data collection. Therefore, each interview takes place within a specific context. According to Blomberg, Giacomi, Mosher, and Swenton-Wall (1993), interviews must be prepared beforehand, by planning which central topics should be addressed and in what order. This allows the interviewer to gradually steer the interviewee's feedback towards specific topics of interest, and to ensure that series of interviews with different people retain a specific internal coherence. The main types of interviews include the directed interview, the semi-directed interview, and the free (open) interview. Considering our goals, the type of interview that seemed to suit our needs best was the semi-directed interview. It allowed us to collect precise data in a reasonable length of time (each interview lasted about 30 minutes) and fostered a genuine dialogue between the interviewer and interviewee, while preserving a framework that was tailored to the goals of the project. We also used closed questions with Likert-type scales (Likert, 1932) to simplify data collection and analysis. In our case, the questions focused on the types of communication tools used by the interviewees.

\subsection{Stakes of PLM in product design}

Designing items of clothing is a cyclical task, in the sense that starting up a collection begins with the analysis of the last collection. At the Devanlay company, the product development cycle currently lasts between 20 and 22 months depending on the collection, before the collection is discontinued. The product's time to market is approximately 13 months to store delivery. For the sake of comparison, the Figure 5, adapted from Segonds (2011), lists the time to market for the main apparel brands. Over the past 25 years, the Lacoste collection has grown from 17 product references in 6 colours in 1885 , to 1200 references in 8 colours in 2012. It stands to reason that the amount of technical data related to these items has grown accordingly.

One of the priorities in implementing a PLM system in Devanlay is to foster creation and innovation in teams by reducing the administrative workload of operational teams. This aims to make it easier to implement a project and to improve the effectiveness of decision-making processes. This, in turn, will lead to reduced time to market and short manufacturing runs, making it possible to respond more efficiently to market needs.

In this context, product development involves five main stages:

- Analysing and structuring the collection: the goal of this stage is to define which items of clothing will be commercialised in the future collection, and in what quantities. This relies on analysing past sales, market needs, and emerging trends.

- Defining the product: the goal here is to define each product in the collection (one collection numbers between 250 and 300 references) in terms of its colour/theme/material/cut characteristics. One source of intermediary data at this stage is the concept sketch file, which specifies all the information related to the product (detailed description, sizing, materials, supplies, etc.). 


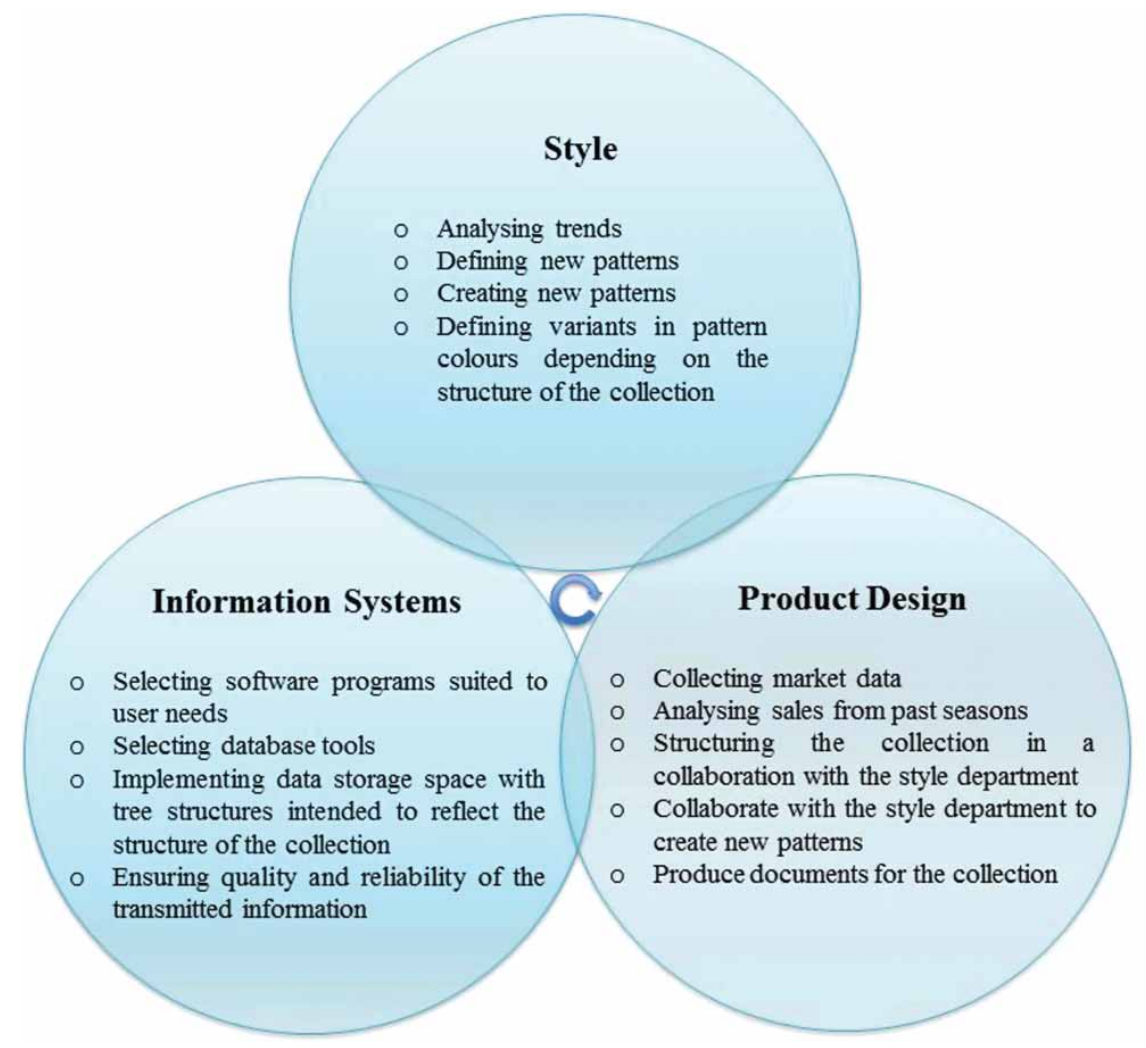

Figure 6. Departments involved in designing a new item of clothing, adapted from Segonds (2011).

- Product design: the goal here is to design and to validate prototypes of items of clothing (a few dozen pieces for each reference) depending on the previously defined criteria of colour/theme/materials/ cut.

- Product development aims to validate the definitive collection and to draft its final documents.

- Product industrialisation: the goal is to produce the technical manufacturing file in order to launch manufacturing orders.

In order to support collaborative work and exchanges of technical data, the section below presents an experiment the purpose of which is to define the collaborative tools used by the company during product design. This allows us to provide adequate specifications for a PLM tool to support the apparel design process.

\section{Analysing the collaborative process for early stage of apparel design}

\subsection{The collaborative process}

Considering the complexity of the collaborative processes involved in the development of an apparel product, as well as the sheer number of actors involved (about 300 people), characterising the exchanges between these people is a crucial starting point in order to understand the collaborative activities which take place within the company. In order to provide the best possible specifications for a collaborative work environment, the first stage of our work aims to identify the main modes of communication used in the company. In order to do this, we carried out a series of 18 interviews with a panel composed of professionals in clothing design at Devanlay, including six persons from the 'style' department, six from the 'product design' department, and six from the IS department (see Figure 6). The latter do not take part directly in the development of a collection, but they play a crucial role in the implementation of new software tools that reflect the work practices of support teams. Finally, this department is located at the crossroads between the company designers, based in Paris, and the engineers from product development, based in Troyes. Therefore, the persons from the IS department are in tune with what improvements could be made to their existing tools for collaboration. The three departments work in close collaboration throughout the early stages of the design process. One of the main goals of our interviews was to identify the forms of communication that were predominantly used within the company. Indeed, the fact that Devanlay is located on two geographically separate sites makes exchanges between sites a crucial element of project success and completion. Analysing these communications, therefore, is a key part of the development of any new tool to support collaboration. 


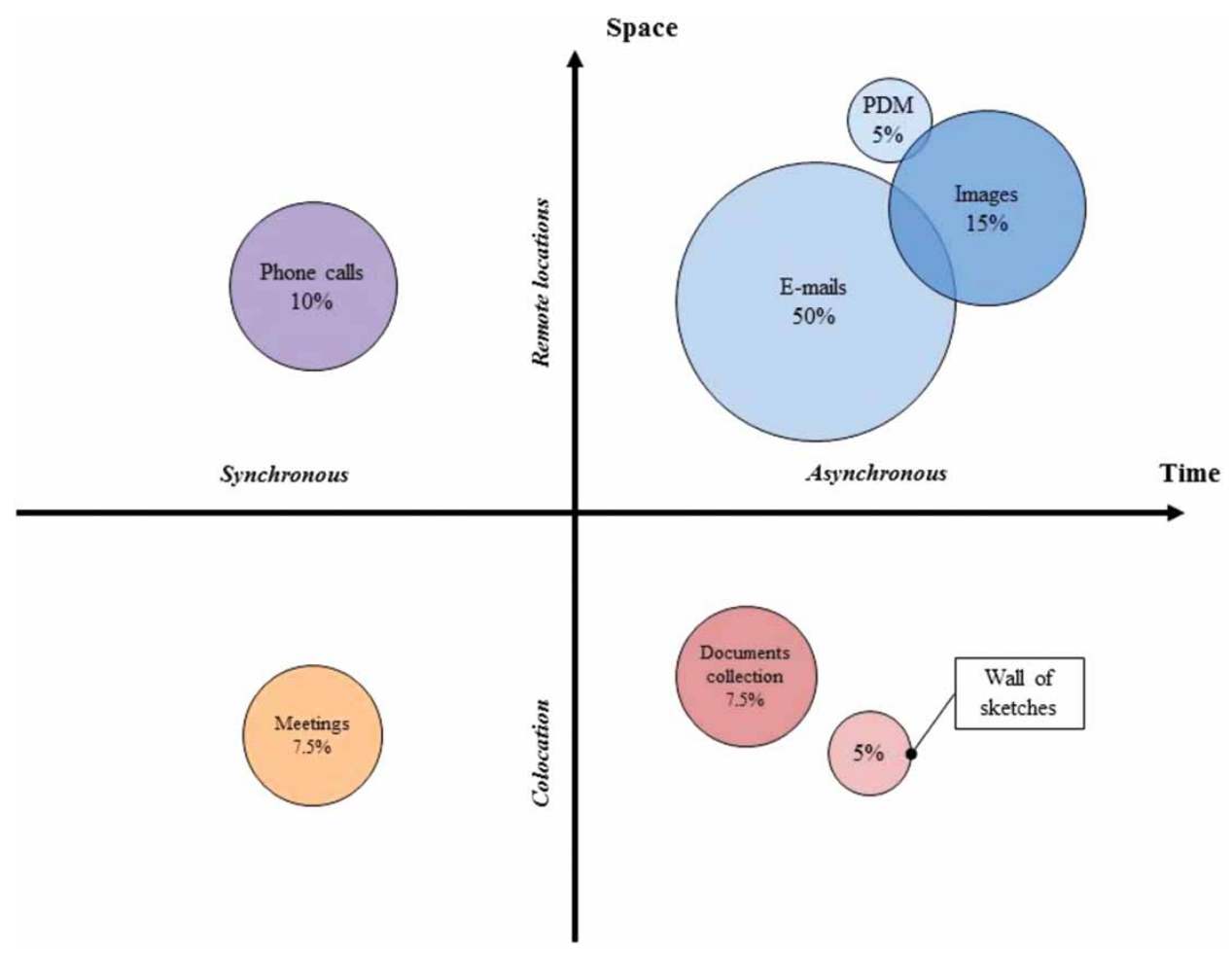

Figure 7. Representation of the main collaboration tools used in Devanlay.

\subsection{Classification of collaborative tools used}

In our case, the questions focused on the types of communication tools used by the interviewees. Questions were grouped into four main topics: means of communication used, department involved in the communication, duration of use of the communication tool, and type of information transmitted. Figure 7 summarises part of the results obtained in these 18 interviews. Means of communication are classified depending on time (synchronous vs. asynchronous communication) and space (colocation vs. remote locations) (Johansen, 1988).

Each circle represents one specific tool for communication. The diameter of the circle is proportional to the average number of occurrences of each topic in the corpus of the 18 interviews. For example, company employees use email in $50 \%$ of all communication situations mentioned in the interviews, confirming the findings presented by Brown (2006). E-mail is the means of communication favoured by the participants in the product development process. One can deduce that a PLM tool that will likely have to provide this means of communication, unless it is also provided through a dedicated email client.

Images are also frequently used as a means of communication ( $15 \%$ of cases). Indeed, in the early stages of the development process for the apparel collection, intermediary representations (Bouchard, Camous, \& Aoussat, 2005) of the product are almost exclusively graphical in nature (e.g. sketches, photos, outlines, etc.). Communication then relies on annotations made directly on the sketches. Another example is the 'wall of sketches', which groups by topic every element of the collection on a magnetised wall. This makes it possible to have an overall view of the harmony present in the collection.

Next, telephone calls have an important part in current communication practices at Devanlay ( $10 \%$ of situations). Telephone is often used as a complement to email in the case of highly technical discussions on the details of product design.

Finally, paper-based communication documents, 'wall of sketches', and interactions with these graphical representations cannot currently be implemented in the digital design process. One final type of collaborative tools are the tools used for managing and communicating data related to the products themselves, also called PDM systems. These are used in 5\% of communications over the course of the product's lifecycle. Some of the key functionalities of these PDM tools should, therefore, be introduced in our proposal for a collaborative environment to assist the early stages of the apparel design process.

All these observations are important to help develop a prototype. We are interested in knowing not just which tools are used, but also what type of information is exchanged. Indeed, based on these results, it seems that the product's intermediary representations hold key information that should be provided by our prototype, such as graphical features. In the section below, we list all the technical data 

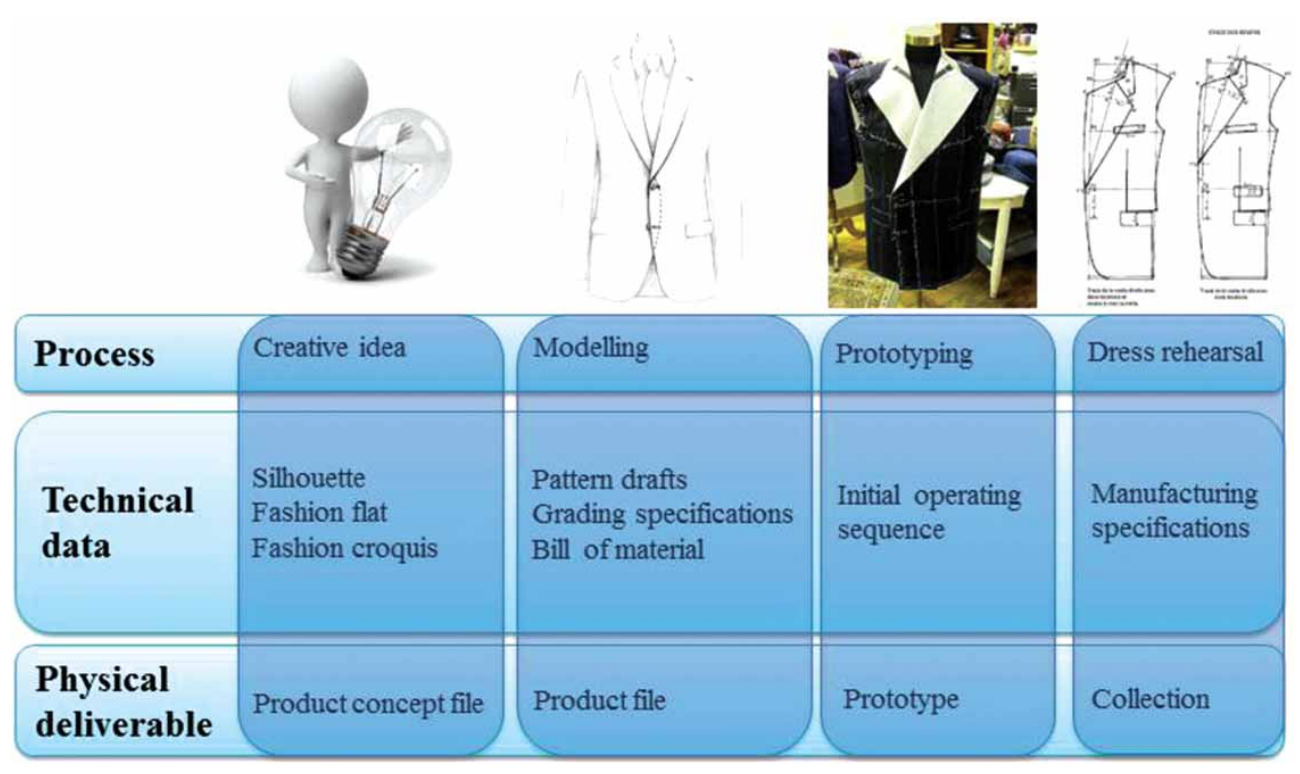

Figure 8. The process of product data creation.

which should be managed throughout the lifecycle process of an item of clothing, as evidenced by our experimentation at Devanlay.

\subsection{Listing the technical data required}

The first element of the design process that produces data on the product is the creative idea, which yields a number of overall characteristics for the product including the silhouette, the fashion flat, and the fashion rough. This data set constitutes the product concept file. Then, the product file includes pattern drafts, grading specifications and bill of material. This marks the end of the stages of product design. Later stages focus on the physical design of the product, starting with the prototyping stage that sets the data for the initial operating sequence. The last stage focuses on the production line, where the collection itself is generated through a process of dress rehearsal. Figure 8 illustrates the successive stages in referencing technical data and physical deliverables.

In addition to listing which collaborative tools were favoured in the company, our analysis thus allowed us to classify the types of intermediary representations used. These specifications will be useful to the design of a collaborative platform.

\section{Conclusions and prospects for future work}

In this paper, we highlighted the key stages in the implementation of a new PLM tool dedicated to the early stages of apparel design. Following a comprehensive review of existing PLM solutions and of the suitability of their functions to the world of apparel design, we mapped and quantified the collaborative exchanges involved in the design of an apparel product in the Devanlay company, based on a series of semi-directed interviews. We then listed the technical data which must be managed by the future system. The emergence of PLM tools, following increasing competition between businesses requires a fine-grained analysis of user needs, in terms of collaboration and exchanges of technical data before designing and deploying the system. The field work reported here allowed us to specify some useful solutions to implement a PLM solution. The next logical step is for us to define a protocol for the agile development of a collaborative tool to support the early stages of the apparel design process. Following this, the tool will be tested and improved based on experience feedback, before being deployed in the Devanlay company.

\section{References}

Amann, K. (2002). Product lifecycle management: Empowering the future of business. Ann Arbor: CimData.

Blomberg, J., Giacomi, J., Mosher, A., \& Swenton-Wall, P. (1993). Ethnographic field methods and their relation to design. In D. Schuler \& A. Namioka (Eds.), Participatory design: Principles and practices (pp. 123-155). Hillsdale, NJ: Lawrence Erlbaum Associates.

Bouchard, C., Camous, R., \& Aoussat, A. (2005). Nature and role of intermediate representations (IR) in the design process: Case studies in car design. International Journal of Vehicle Design, 38(1), 1-25.

Brown, J. (2006). The product lifecycle collaboration benchmark report - the product profitability "X-Factor". Boston: Aberdeen Group.

Dul, J., \& Hak, T. (2008). Case study methodology in business research. Burlington: Butterworth-Heinemann.

El Kadiri, S., Pernelle, P., Delattre, M., \& Bouras, A. (2009). Current situation of PLM systems in SME/SMI: Survey's results and analysis. Paper presented at the 6th International Conference on Product Lifecycle Management, Bath.

Garetti, M., Terzi, S., Bertacci, N., \& Brianza, M. (2005). Organisational change and knowledge management in PLM 
implementation. International Journal of Product Lifecycle Management, 1(1), 43-51.

Holzinger, A. (2005). Usability engineering methods for software developers. Communications of the ACM, 48(1), 71-74.

Howard, T. J., Culley, S. J., \& Dekoninck, E. (2008). Describing the creative design process by the integration of engineering design and cognitive psychology literature. Design Studies, 29(2), 160-180.

ISO. (2003). 10007:2003, Quality management systems: Guidelines for configuration management. Geneva: Author.

Johansen, R. (1988). Groupware: Computer support for business teams. New York, NY: The Free Press.

Le Duigou, J., Bernard, A., \& Perry, N. (2011). Framework for Product Lifecycle Management integration in small and medium enterprises networks. Computer-Aided Design and Applications, 8(4), 531-544.

Likert, R. (1932). A technique for the measurement of attitudes. Archives of Psychology, 140, 1-55.

Liu, Y. J., Zhang, D. L., \& Yuen, M. M. F. (2010). A survey on $\mathrm{CAD}$ methods in $3 \mathrm{D}$ garment design. Computers in Industry, 61(6), 576-593.

Maguire, M. (2001). Methods to support human-centred design. International Journal of Human Computer Studies, 55(4), 587-634.

Maranzana, N., Segonds, F., Lesage, F., \& Nelson, J. (2012). Collaborative design tools: A comparison between free software and PLM solutions in engineering education. Paper presented at the 9th International Conference on Product Lifecycle Management-PLM'12, Montréal.

Pahl, G., Beitz, W., Feldhusen, J., \& Grote, K. H. (2007). Engineering design - a systematic approach. Londres: Springer.
Pezeshki, C., Frame, R. T., \& Humann, B. (2004). Preparing undergraduate mechanical engineering students for the global marketplace-new demands and requirements. Paper presented at the ASEE Annual Conference Proceedings, Salt Lake City.

Prasad, B. (1996). Concurrent engineering fundamentals - integrated product and process organization (vol. 1). London: Prentice Hall.

Schuh, G., Rozenfeld, H., Assmus, D., \& Zancul, E. (2008). Process oriented framework to support PLM implementation. Computers in Industry, 59(2-3), 210-218.

Segonds, F. (2011). Contribution to the integration of a collaborative design environment in the early stages of design $(\mathrm{PhD})$. Paris: Arts et Metiers ParisTech.

Sharifi, S., \& Pawar, K. (2001). Product development strategies for agility. In A. Gunasekaran (Ed.), Agile manufacturing: The 21st century competitive strategy (pp. 175-192). Amsterdam: Elsevier.

Sohlenius, G. (1992). Concurrent engineering. CIRP Annals Manufacturing Technology, 41(2), 645-655.

Volino, P., Cordier, F., \& Magnenat-Thalmann, N. (2005). From early virtual garment simulation to interactive fashion design. CAD Computer Aided Design, 37(6), 593-608.

Winner, R. I., Pennell, J. P., Bertrand, H. E., \& Slusarczuk, M. M. (1988). The role of concurrent engineering in weapons system acquisition. Alexandria, VA: Institute for Defense Analyses.

Zina, S., Lombard, M., Lussent, L., \& Henriot, C. (2006). Generic modeling and configuration management in product lifecycle management. International Journal of Computers, Communications \& Control, 1(4), 126-138. 